\title{
Anti-addiction vaccines
}

\section{Xiaoyun Shen ${ }^{1}$, Frank M. Orson ${ }^{1,3}$ and Thomas R. Kosten ${ }^{2,3 *}$}

Addresses: ${ }^{1}$ Immunology, Allergy \& Rheumatology, Department of Medicine, Baylor College of Medicine, Houston, TX 77030, USA; ${ }^{2}$ Department of Psychiatry, Baylor College of Medicine, Houston, TX 77030, USA; ${ }^{3}$ Veterans Affairs Medical Center, 2002 Holcombe, Houston, TX 77030, USA

* Corresponding author: Thomas R. Kosten (kosten@bcm.tmc.edu)

FI000 Medicine Reports 20II, 3:20 (doi:10.3410/M3-20)

This is an open-access article distributed under the terms of the Creative Commons Attribution-Non Commercial License (http://creativecommons.org/licenses/by-nc/3.0/legalcode), which permits unrestricted use, distribution, and reproduction in any medium, provided the original work is properly cited. You may not use this work for commercial purposes.

The electronic version of this article is the complete one and can be found at: http://f1000.com/reports/m/3/20

\begin{abstract}
Despite intensive efforts to eradicate it, addiction to both legal and illicit drugs continues to be a major worldwide medical and social problem. Anti-addiction vaccines can produce the antibodies to block the effects of these drugs on the brain, and have great potential to ameliorate the morbidity and mortality associated with illicit drug intoxications. This review provides a current overview of antiaddiction vaccines that are under clinical trial and pre-clinical research evaluation. It also outlines the development challenges, ethical concerns, and likely future intervention for anti-addiction vaccines.
\end{abstract}

\section{Introduction}

Globally, UNODC (United Nations Office on Drugs and Crime) estimates that, in 2009, between 149 and 272 million people, or $3.3-6.1 \%$ of the population aged 15-64, used illicit substances at least once in the previous year. About half of those are estimated to have been current drug users (i.e., they used illicit drugs at least once during the month prior to the date of assessment). Of the current drug users, it is estimated that there is a range of 15-39 million "problem drug users" globally. This subgroup of drug users is most likely to come to the attention of healthcare services and law enforcement authorities, and has been estimated to cause the main public-health and public-order burden. After cannabis, amphetamine group substances are the most common, followed by cocaine and opiates. The last three drugs are highly addictive and cause enormous economic, health, and behavior problems [1].

Current medications for drug abuse have only had limited success for drugs such as cocaine, nicotine, methamphetamine, and heroin. The recent advent of human trials of vaccines against abused drugs is therefore a welcome development. The antibodies generated from anti-drug vaccines can bind the target drug and form the antibodydrug compound molecules that are too large to cross the blood-brain barrier. This reduces the rate and quantity of drug entry into the brain and inhibits the psychoactive effects of the drug [2-6]. If this antibody capacity is sufficiently large, it can lead to a reduction in drug use or limit the possibility of a drug relapse. Anti-addiction vaccines are designed for the following goals: (a) helping addicts achieve initial abstinence; (b) preventing relapse after a drug-dependent patient completes withdrawal and is attempting to remain drug-free; (c) enhancing behavioral therapies when combined with other anti-addiction medications; and (d) potentially preventing addiction in high-risk populations.

The history of anti-addiction vaccines starts nearly 40 years ago. The proof of principle for an anti-addiction vaccine was first demonstrated by two studies. In 1972, Berkowitz and colleagues [7] published their creation of a morphine vaccine in animals. Using rats, they administered a morphine hapten linked to bovine serum albumin (BSA, a carrier protein) and created anti-morphine antibodies. These antibodies reduced the concentration of free morphine in the plasma of their vaccinated rats. In 1974, Bonese created a similar vaccine in primates, and the vaccinated rhesus monkey primates decreased their self-administration of heroin [8]. Unfortunately, this work did not move forward to human use, at least in part because other neuropharmacological approaches that blocked abstinence symptoms (methadone) or prevented 
relapse (naltrexone) were introduced and preferred by patients $[9,10]$. More recently, given the lack of success of these and other approaches, anti-addiction vaccines have now been trialed in humans.

The data from cocaine and nicotine vaccine trials suggest that many patients may not produce a sufficient antibody response for clinical efficacy, but those patients who do attain high levels of antibodies are helped to remain abstinent [11-12]. If extending this technology to other abused substances is successful, it will be a tremendous benefit to have innovative pharmacotherapies rapidly available, especially as new "designer drugs" are introduced. Indeed, anti-addiction vaccines are in various stages of development for quite a broad array of abused drugs, including cocaine, nicotine, methamphetamine, and heroin [13-15]. Vaccine efficacy depends on many critical factors, such as antibody specificity, affinity, and antibody concentration (titer), which are affected by the design of the vaccine conjugate, the dose of the vaccine, the adjuvant selection, the frequency of vaccinations, the time interval between immunizations, and maybe the poorly understood genetic variations among individuals.

\section{Cocaine vaccines}

\section{Background and development}

Cocaine addiction is a global health problem. In the United States alone, government surveys indicate that 2.4 million or more Americans aged 12 years or older are current users of cocaine [16]. Its use has penetrated all levels of society, and the ills it has created are evident in both crime (about $30 \%$ of federal and state prisoners were regular cocaine users before incarceration) and health statistics (from overcrowded emergency rooms to individual acute psychotic reactions, heart attacks, or strokes). A therapeutic vaccine is particularly critical for cocaine addiction since there is currently no US Food and Drug Administration (FDA)-approved pharmacotherapy to encourage withdrawal, or prevent the relapses that consistently derail most addicts' recovery efforts [17]. The current cocaine vaccine's development started in 1994 under Dr. Barbara Fox at the ImmuLogic Pharmaceutical Corporation with support from the National Institute of Drug Abuse [2]. It was produced by attaching the cocaine to the surface of an antigenic carrier protein, which for this first generation vaccine was deactivated cholera toxin $B$ subunit protein combined with the FDA-approved human adjuvant alum. Both the carrier protein and adjuvant used in this cocaine trial are different from those used in the first animal morphine vaccine studies, although the proof of principle is the same. Along with other labs, these early studies showed that conjugate cocaine vaccines could elicit strong antibody responses that blocked the pharmacological effects of the drug.

\section{Clinical trials}

In 1996, a Yale University group was the first to use a cocaine conjugate vaccine in humans, and Phase I and IIa studies with this cocaine vaccine (TA-CD) were completed by 2005 [17]. In the phase IIa studies, where human laboratory trials assessed dosing requirements and short-term risks, most patients made clinically relevant quantities of cocaine-specific antibody, and so far have had few side effects $[18,19]$. The estimate of the needed antibody level was based on the results of a human laboratory study demonstrating that TA-CD substantially decreased the intoxicating effects of smoking cocaine in those generating antibody levels above $20 \mu \mathrm{g} / \mathrm{ml}$ [20]. A later Phase IIb study (a randomized human outpatient trial to assess clinical efficacy) showed that $40 \%$ of the patients made sufficiently high antibody levels (over $43 \mu \mathrm{g} / \mathrm{ml}$ ) after vaccination and significantly reduced their cocaine use for over 2 months.

The response to cocaine vaccines occurs in two phases. The initial phase lasts about 8-12 weeks during which an initial series of five vaccinations results in a relatively high level of antibodies in about $40 \%$ of vaccinated addicts and another 35\% have antibody levels sufficient to block one or two cocaine doses, the latter of which is especially useful for relapse prevention in patients already abstinent [18]. The antibodies are produced to cocaine as well as cholera toxin $\mathrm{B}$, since the polyclonal antibody response includes the cocaine chemically attached to the cholera toxin. Virtually everyone will produce substantial antibody responses to the cholera, but the reasons why about $25 \%$ of patients produce low or minimal levels of anti-cocaine antibodies are not known. This non-response issue is being actively investigated with a variety of very interesting leads related to human genetics and the production of immunological tolerance for particular substances.

The antibody levels may decline substantially in the second phase (beyond 12 weeks) in the patients who produced therapeutic levels of antibody to cocaine in the initial phase, and a booster vaccination is often needed. Rather than needing the full series of five vaccinations again, however, a single vaccination may be sufficient to elevate antibody levels back to their therapeutic levels for about 3 months. Thus, for a period of protection lasting 2 years, patients would need to get about six additional boosters given as one every 3 months. Exposure to cocaine alone will not provoke an increase in antibodies because the cocaine molecule is unable to activate memory $\mathrm{B}$ cells by cross-linking the antibodies expressed on their surface. 
However, after boosting with the conjugate vaccine, newly produced antibodies in sufficient quantity will be able to very rapidly (within seconds) bind most of a usual dose of cocaine when it enters the bloodstream, and again prevent the cocaine from leaving the blood vessels and entering the brain, heart, or other organs. This reduces the typical drug effects on the various organ systems in the body. Because the antibody-cocaine complex is too large to pass thorough the blood-brain barrier, the cocaine is then metabolized in the blood and liver to inactive metabolites by one of three mechanisms: spontaneous hydrolysis, tissue esterases (especially in the liver), or butyryl cholinesterase (in the bloodstream) [21]. These metabolites do not bind to the cocaine antibodies because of their different chemical structures and are simply excreted from the body.

Phase I and II studies with the cocaine vaccine were very successful, in part because the cocaine was rapidly sequestered and metabolized. This resulted from the advantageous combination of a good antibody response from the cholera toxin carrier and the spontaneous and enzymatic hydrolysis of cocaine into inactive metabolites. This type of rapid metabolism does not exist in the blood stream for other abused drugs, such as nicotine or methamphetamine. When these other drugs are bound by antibodies, the drug is slowly metabolized in the liver or other tissue sites, or excreted unchanged [22]. As a result, these other compounds circulate in the bloodstream much longer when bound by antibody.

\section{Current status}

The notable success of the first placebo-controlled clinical trial of a cocaine vaccine [18], as well as the relative ease with which these vaccines can be manufactured, has encouraged a multi-site study of the cocaine vaccine to move forward quickly. Currently, the cocaine vaccine (TA-CD) is being evaluated in an ongoing multisite, Phase IIb clinical trial. This 4-month, double-blind, randomized, placebo-controlled, multi-center study is comparing the effect of the cocaine vaccine to placebo in reducing cocaine use in 300 treatment-seeking, cocainedependent individuals. Patients receive five vaccinations over a period of 12 weeks and some subjects will likely attain therapeutic antibody levels in weeks $6-8$, after the first three injections. Based on the success of this vaccine in earlier clinical trials, this cocaine vaccine shows promise to be one of the first anti-addiction vaccines to be approved by the FDA for human use.

\section{Nicotine vaccines}

\section{Background and development}

Smoking is a global healthcare problem. The World Health Organization estimates that there are 1.3 billion smokers worldwide today and more than 5 million tobacco-related deaths each year [23]. If current smoking patterns continue, smoking will cause some 10 million deaths each year by 2020 [24]. To date, three medications are FDA-approved for smoking cessation: nicotine replacement therapy, sustained-release bupropion, and varenicline $[25,26]$. Despite the relative efficacy of these first-line medications, long-term abstinence rates remain disappointingly low, plus, many drug abusers relapse after one quit attempt using the available pharmacotherapies. The CDC (Centers for Disease Control and Prevention) estimates that, among the 45 million adult smokers in the United States, almost 75\% want to quit, but less than $5 \%$ of those who try to quit remain smokefree after 12 months [27]. Thus, efforts to develop new treatments including nicotine vaccines are continuing.

Nicotine does not have the advantage of a serum enzyme that breaks it down into an inactive metabolite in the bloodstream. Lacking such a serum enzyme would make a successful nicotine vaccine more difficult if the only goal was to prevent deliberate override of the antibody levels. However, nicotine vaccines may nonetheless prove as effective as cocaine vaccines because the antibody levels needed for blocking nicotine effects are about ten times lower for nicotine than cocaine, and those being vaccinated are typically very motivated to stop smoking and do not have the ambivalence about abstinence that is common among cocaine and other illicit drug users $[11,28]$. An early nicotine vaccine significantly reduced drug distribution to the brain from single nicotine doses, even after animals were chronically treated with total nicotine daily doses that exceeded the estimated binding capacity of antibody by 33-fold [28]. This reflected the fact that nicotine metabolism was able to continue despite a portion of the drug being bound to antibody, permitting some antibody to be available for binding an additional nicotine dose. This remarkably greater efficacy than binding capacity is probably due to the rapid on and off binding rates for nicotine as a small molecule that is bound by a single antibody-combining site. Nevertheless, having quantitatively high antibody responses to clinical vaccines is critical to success. Overall, nicotine vaccines could have significant success relatively soon since they can be manufactured relatively inexpensively, the total smoking population worldwide is very large, motivation to quit smoking is relatively strong, and finally patients are quite unlikely to try to deliberately override the antibody capacity, unlike cocaine patients. The low cost of a nicotine vaccine will also facilitate widespread distribution of the vaccine for public health purposes to a wide range of less wealthy populations in both developed and developing nations' healthcare systems. 


\section{Clinical trials}

Because of the substantial market for smoking cessation products, development of a vaccine against nicotine addiction has caught the interest of the pharmaceutical industry. As a result, three pharmaceutical companies have moved nicotine vaccines forward to human studies [29].

\section{NICOO2}

Phase II trials with NIC002 (also known as Nicotine Qbeta or CYT002-NicQb) from Cytos Biotechnology/ Novartis were conducted in 341 smokers, and the outcome data were available from 239 study subjects who were divided into low, medium, and high responders according to their nicotine antibody levels. There was no difference in abstinence rates among the low and medium responders and placebo groups. The top third of the responders had higher abstinence rates at the 6and 12-month follow ups [30]. However, side effects (including flu-like symptoms) occurred in $69.4 \%$ of subjects. In 2007, Cytos Biotechnology entered into a licence agreement with Novartis and, in 2008, Novartis began a new Phase II trial in 200 cigarette smokers with a reformulated vaccine with fewer side effects. However, interim analysis showed that the primary endpoint (continuous abstinence from smoking from weeks 8-12 after start of treatment) was not achieved, possibly because NIC002 failed to induce sufficiently high antibody titers [31].

\section{TA-NIC}

Celtic Pharma completed a Phase II, double-blind, randomized, placebo-controlled, multicenter, doseranging study of 100 or $250 \mu$ g of TA-NIC (a recombinant cholera toxin conjugate vaccine) to assess the efficacy and safety of the vaccine as an aid to smoking cessation in 2009, but the results have not yet been released [32].

\section{NicVAX}

The most advanced nicotine product is NicVAX (a bacterial exoprotein conjugate vaccine) by Nabi Biopharmaceuticals/GlaxoSmithKline. During 2004 to 2006, Nabi conducted five Phase I/II clinical studies involving more than 475 subjects and demonstrated that NicVAX was well-tolerated, highly immunogenic, gave a dose-dependent increase in antibody concentrations, and showed a clinical proof of concept for efficacy in smoking cessation (clinical response rates were highly correlated with antibody concentration). Significantly, the data in the Phase IIb proof-ofconcept study showed a correlation between antibody concentration and the ability of subjects not only to quit smoking but also to remain abstinent up to 12 months [32].
In 2007, Nabi announced the successful completion of our Phase IIb trial of NicVAX. The Phase IIb study was a double-blind, placebo-controlled, dose-ranging study designed to establish proof of concept and the optimal dose and regimen for the Phase III program. The trial enrolled a total of 301 heavy smokers who smoked an average of 24 cigarettes per day prior to enrollment. The $30 \%$ of participants who developed the highest level of nicotine antibodies (61 of 201) showed a continuous abstinence at 8 weeks, between weeks 19-26 compared with subjects who received placebo, and abstinence rate was almost three times that of the placebo group after 12 months (16\% in $400 \mu \mathrm{g}$ group, $14 \%$ in the $200 \mu \mathrm{g}$, and $6 \%$ in the placebo group). In addition, vaccinated smokers who failed to quit but showed a high antibody response smoked a median of only 10 cigarettes per day while in the study, compared to their own baseline value of 20 cigarettes per day before treatment. In the remaining $70 \%$ of vaccinated participants, abstinence rates were no better than placebo. These trials did not demonstrate nicotine vaccines to be superior to placebo when including all vaccinated subjects because only a third of those vaccinated develop sufficient levels of antibody to block the effects of nicotine [32].

However, in July 2008, Nabi reported results of an improved immunization schedule, which was based on the $400 \mu \mathrm{g}$ dose and six applications of the vaccine. Based on this schedule, $80 \%$ of the subjects achieved the target antibody level at 14 weeks, which compares to only $50 \%$ of subjects with the prior immunization schedule. Nabi started a Phase III trial in 2008, which was a double-blinded, placebo-controlled trial with 1,000 patients. The primary endpoint of the study was the abstinence rate for 16 weeks ending at 12 months. Abstinence was evaluated by self-reported cigarette consumption and biologically verified by exhaled carbon dioxide. Secondary endpoints included the abstinence rate at various time intervals, safety, and immunogenicity and the effect of NicVAX on withdrawal symptoms, cigarette consumption, smoking satisfaction, and nicotine dependency. Nabi has announced the results of the first NicVAX(R) Phase III clinical trial recently; the smoking cessation immunotherapy failed to meet its primary endpoint of significantly greater abstinence in those vaccinated compared with the placebo group [32]. However, this assessment was done several months after the anti-nicotine antibody levels had fallen well below expected therapeutic levels. Nabi is awaiting the results of a second Phase III trial, but it has suffered similar design problems; that is, treatment efficacy was assessed after the active agent responsible for the therapeutic effect (e.g., high antibody levels to nicotine) had been gone for several months [33]. 


\section{Development considerations}

Nicotine vaccines could have an important advantage in that they can have a prolonged effect on the immune system (for 6-12 months), and this could reduce the relapse rate. Another advantage of the vaccine approach is that daily administration of the drug is not required; only occasional booster shots are needed to maintain an adequate antibody titer. However, there has been inconsistency in the degree of antibody response; some people do not achieve adequate antibody titers. Possible disadvantages of nicotine vaccines include the necessity for multiple injections and the time delay before an effective immune response is achieved. Nicotine vaccines are in Phase I and III trials and, if successful, they will contribute to the fight against tobacco addiction in an innovative way.

\section{Vaccines for methamphetamine addiction}

Methamphetamine is a highly addictive and toxic drug of abuse with potent central and peripheral sympathomimetic effects [34]. Its potent effects include an elevation of pulse rate and blood pressure, and an increased level of alertness. Pharmacokinetic studies have shown that both cocaine and methamphetamine have fast uptake (reaching peak brain concentrations within several minutes); the drug clearance from the human brain is fast for cocaine, but slow for methamphetamine (hours) [35]. Methamphetamine has a plasma half-life of 12 hours, and the drug may last between 4 and 24 hours [36]. It has been shown that abuse of the drug leads to high levels of accumulation of methamphetamine in most body organs, in humans [37] as well as non-human primates [38]. This widespread and long-lasting drug distribution parallels its long-lasting behavioral effects, and is likely to contribute to various medical complications including stroke, insomnia, excitability, seizures, panic attacks, psychosis, and aggressive behavior $[39,40]$.

Methamphetamine use and addiction has grown at alarming rates over the past two decades in the United States and in Southeast and East Asia [41,42], and the high rate of relapse in the patients undergoing methamphetamine withdrawal underscores the difficulty in developing an effective therapy for methamphetamine addiction [43]. According to the 2008 National Survey on Drug Use and Health, 850,000 Americans aged 12 or older used methamphetamine at least once in the year prior to being surveyed, with past-month users reaching 314,000 [44]. The National Drug Threat Assessment states that methamphetamine is "a principal drug threat" to the United States and that $31 \%$ of state and local law enforcement agencies nationwide consider it as the principal drug threat [45]. Currently, there are no FDAapproved medications for treating methamphetamine addiction, so a successful vaccine against methamphetamine could have a substantial impact on addiction, as well as on reducing one of the major risks for HIV transmission worldwide.

Over the past decade, a number of labs have been working on evaluating the best composition of a vaccine for methamphetamine by considering hapten design, selection of the carrier protein, the chemical positioning of a linker between the target antigen and the carrier protein, and choice of the best adjuvant, which is crucial for proper immune stimulation both in terms of amount of antibody elicited and antibody specificity [46-48]. Janda's group has recently reported three methamphetamine conjugates that are able to generate substantial antibody titers $(45-108 \mu \mathrm{g} / \mathrm{mL})$ and moderate affinity $(82,130$, and $169 \mathrm{nM})$ [47]. The data from our lab have shown that high titer antibodies can be elicited and maintained for 3 months by administration of methamphetamine conjugates in rodents, depending on the conjugate construction and the adjuvants used. This elevated antibody level is associated with the reduction of methamphetamine-stimulated locomotor activity in the vaccinated animals (Orson, unpublished data). Furthermore, our data have suggested that methamphetamine binding to antibody is equivalent to high affinity monoclonal methamphetamine antibody [4-6] in enzyme-linked immunosorbent inhibition assays, using polyclonal antibodies generated by KLH-S-Meth or OMPC-S-Meth (Orson, unpublished data).

In parallel, Owens and his colleagues have been evaluating a passive immunotherapy approach using the monoclonal antibodies for methamphetamine. Passive immunotherapy involves the administration of the preformed antibodies via intravenous, subcutaneous, or intramuscular injection. The antibodies can be in the form of polyclonal serum or purified IgG from animals that were immunized with a drug-protein vaccine [49]. The monoclonal antibodies injected passively bind the abused drug and act by the same pharmacokinetic as the polyclonal antibody-produced vaccines. In vivo pharmacokinetics have shown that high concentrations of antimethamphetamine monoclonal antibodies can produce a sustainable equilibrium shift of methamphetamine out of the brain and into the blood stream, as measured by substantial reductions in methamphetamine brain concentrations over time accompanied by substantial increases in methamphetamine serum concentrations $[5,6]$. The rate of association and dissociation of the antibody binding to the drug may also influence the rate of drug entry to, and exit from, the brain. By slowing methamphetamine's entry into the brain, the antibodies may be effective in reducing the amount of drug in the 
brain, thereby reducing the pharmacological effects of the drug. These antibody-induced reductions in methamphetamine volume of distribution, clearance from the blood stream, and substantially increased serum protein (predominantly antibody) binding are why antibody medications are classified as pharmacokinetic antagonists; that is, they favorably change the concentrationtime course of methamphetamine in brain and other organ systems. In addition, the passive administration of high-affinity monoclonal antibodies has also shown to reduce methamphetamine self-administration in rats [50] and to reduce locomotor activity in rats given low and moderate doses of methamphetamine, but not at doses that significantly exceeded the antibody-binding capacity for high-dose methamphetamine $[51,52]$.

\section{Development considerations}

While the published human cocaine/nicotine studies support the feasibility of anti-methamphetamine vaccines, the methamphetamine vaccines that generate efficacious levels of antibodies with sufficient binding affinity to the drug are not yet sufficiently characterized to proceed to clinical studies. Hapten design, carrier protein, and use of adjuvants are critical for development of an efficacious vaccine. The OMPC (outer membrane protein complex of the bacterium Neisseria meningitidis group B) and KLH (keyhole limpet hemocyanin) are the highly immunogenic foreign carrier proteins that have been commonly used in vaccine formulation [53], and our preliminary data indicated that OMPC is particularly attractive as a carrier for the anti-addition conjugate vaccines, since it elicits early, high-level antibody responses to the drug. The methamphetamine vaccines may be evaluated in combination with the currently licensed adjuvants including aluminum salts (alum), MF59, and monophosphoryl lipid A [53]. The influence of average antibody-binding affinity and kinetics from these vaccines can be examined using techniques including surface plasmon resonance, isothermal titration calorimetry, and fluoresenced thermopheresis. Animal models, such as methamphetamine self-administration and the locomotor assay, can be applied to evaluate the vaccines against repeated selfdosing with methamphetamine and to assess the degree to which the antibodies can inhibit the reinforcement effects of methamphetamine.

\section{Vaccines for opiate addiction}

All opioids, including morphine, heroin, and prescription analgesics such as Vicodin and OxyContin, have extremely high abuse potential. Dependence on these drugs has been termed a "chronic, relapsing disease," [54] and is associated with a multitude of health and social problems, such as increased risk for HIV, mortality, crime, unemployment, and breakdown of interpersonal relationships [55]. Global heroin consumption was 340 metric tons in 2008, of which Europe (excluding Russia and Turkey) consumed the most (88 metric tons, $26 \%$ of global consumption), followed by Russia (70 tons; $21 \%$ ), China ( 45 tons; $13 \%$ ) and the United States ( 22 tons; $6 \%$ ) [1]. In 2007, 3.8 million Americans reported using heroin at some point in their lives, with $58 \%$ of the 366,000 current-year users meeting criteria for dependence or abuse [56].

Both methadone maintenance and naltrexone are currently used as treatment for opiate dependence $[9,10]$. However, it has been shown that less than $25 \%$ of heroin addicts remain abstinent after methadone maintenance treatment [57] and $60 \%$ of heroin addicts lapse following inpatient treatment [58]. In addition, these therapies are associated with a number of problems, such as high attrition rates within the first month [59], and reliance on methadone clinics for the three-times-weekly administration. Besides, methadone is a full-opioid agonist itself, therefore it is susceptible to abuse and overdose, including adverse reactions such as respiratory depression. Furthermore, both methadone maintenance and naltrexone programs are very costly (in 1996 alone, the United States spent approximately $\$ 21.9$ billion dollars on heroin addiction [60], and so are less feasible in some countries [55]. Therapeutic vaccines have the potential as treatments to address these problems.

As discussed above, the first anti-addiction vaccine development was directed to vaccines for opiate addiction $[7,8]$. Other early studies also showed that certain morphine protein conjugates could produce antibodies with specificity to heroin and 6-acetylmorphine, as well as morphine itself, and that the binding specificity may differ depending on the hapten used [61-63]. Opiate vaccines are now being revisited, almost 40 years after they were initially studied [64-67], in order to offer an option to produce long-lasting morphine/heroin antibodies that are specific for heroin and its psychoactive metabolites at a sufficient level to block the pharmacological effects. These antibodies would act as an opiate antagonist without the aforesaid negative side effects associated with naltrexone/ naloxone. Anton and Lef [65] demonstrated that a $6^{\prime}$ esterlinked morphine-tetanus toxoid vaccine was able to trigger and establish adequate antibody titers and prevent reacquisition of heroin self-administration in rats. However, similar to the earlier study [8], a total of four boosts were required over a 60-day period to reach adequate titers, and biweekly boosts were needed to keep titer levels high over the period of a year. Recently, Janda and his colleagues have published their study using vaccines with 
heroin-like and morphine-like haptens linked to the adjuvant KLH (keyhole limpet hemocyanin). The results showed that the polyclonal antibodies from a heroin-like vaccine had micromolar affinity to 6-acetyl morphine, heroin, and morphine and prevented rodents from acquiring the habit of heroin self-administration or showing the anti-nociceptive effects of heroin. Conversely, antibodies generated by morphine-like vaccine only had adequate affinity for morphine and a reduced binding for heroin, but no affinity for 6-acetyl morphine; in addition, the morphine-like vaccine was not effective for preempting heroin administration [67].

Our recent studies have demonstrated that high to moderate levels of anti-morphine antibodies are elicited by morphine-KLH conjugates together with either alum or monophosphoryl lipid A in rodents $[68,69]$. In agreement with the previous studies [61-63], our study has shown that polyclonal antibodies generated by morphine vaccines were able to bind to morphine and its metabolites (6-acetyl morphine, 3-glucuronide morphine, and 6-glucuronide morphine), but with nanomolar affinity [69]. This cross reactivity is critically important, since heroin is a prodrug that is rapidly converted to the pharmacologically active opiates 6-acetyl morphine and morphine by esterases present in both the periphery and the central nervous system [70]. In addition, our efficacy studies demonstrated a significant inhibition of morphine-induced analgesia $[68,69]$ and conditioned rewarding effects of morphine [69] in the immunized animals. These behavioral changes in the vaccinated rats were at least in part due to sequestration of the drug in the blood and reduction of the drug levels in the brain by antibodies [70].

Although morphine and heroin can both be blocked by antibodies from a single type of vaccine, at least five different vaccine types may be needed to block all the types of synthetic opiates that have now been manufactured as alternatives to morphine due to their widely varying chemical structures. Because prescription opiate abuse has overtaken heroin as the major opiate abuse problem in the United States, a vaccine approach to blocking heroin abuse will be less effective in the clinic. However, in the developing world, such as Southeast Asia, the Middle East (Iran) and Mexico, where morphine and heroin are the opiates most commonly abused, an effective vaccine would be life-saving and very cost effective. By building on previous research, designing methodologically sound studies and systematically assessing patient outcomes during the clinical trial and 6-12 month follow-ups, such vaccines can hopefully win FDA approval and then assist in combating this serious public-health issue.

\section{Challenges and implications Challenges in delivering clinically effective anti-addiction vaccines}

An efficacious vaccine elicits good quality antibodies that maintain at sufficient levels throughout a sustained period of several months after the initial vaccination series and then after each booster vaccination. Clinical trials of cocaine and nicotine vaccines so far have reported modest efficacy. The abstinence rates among those vaccinated against nicotine have been no better than placebo overall, but the rates have been superior to placebo in the third who achieved therapeutic antibody levels. So, enhancing the proportion of responders and the magnitude of antibody responses will be critical for making this approach broadly useful. Increasing the number of doses and/or the size of the dose may improve immunogenicity [33], but improved adjuvants may offer the best route for increasing responses. However, these changes may also increase adverse effects so that the safety and efficacy of the revised dosage schedules will need to be established. Nicotine vaccines will need to be shown to be more effective than nicotine replacement therapy, bupropion, varenicline, and any new cessation aids in order to be adopted.

The cocaine vaccine was conceived primarily as an agent for patients who could abstain from cocaine use for a limited period of time but needed help with maintaining that abstinence. This could work by inhibition of a phenomenon that occurs across addictions called the "priming effect" [71]. In the absence of an anti-cocaine mechanism, cocaine use after a period of abstinence markedly intensifies craving and increases the risk for continuing into a binge pattern of abuse and relapse. However, it was noted in Phase IIb cocaine trials that some subjects who continued high-level cocaine use did not appear to override the antibody blockade of cocaine effects [18]. Therefore, anti-addiction vaccines may, in high responders at least, also inhibit deliberate attempts to override the vaccine's blockade by using more than an initial one or two drug doses.

The behavioral challenges for any successful vaccination program start with the need to have 2-3 months where the patient can be brought to a treatment site for five vaccinations. During these 2-3 months, the patients could be vulnerable to relapse if they have already discontinued drug use. While this drug abuse alone does not interfere with the vaccine's ability to induce the required antibody production, it is critical that the patient gets these vaccinations at appropriate times over the 3 months (e.g., 2, 4, 8, and 12 weeks after the initial vaccination) and continued abuse may result in failure to 
appear for these follow-up visits. Thus, other treatment interventions will be valuable to insure that compliance with the schedule of vaccinations is maintained and such interventions could vary from residential substance abuse care to outpatient contingency management in which patients are paid to come for the vaccinations with an escalating pay schedule for each vaccination obtained. Alternatively, monoclonal antibodies could provide passive immunity while the acquired immunity is built up, although such antibodies are expensive and can produce adverse side effects [72].

\section{Ethical and legal challenges}

Apart from development hurdles, ethical, legal, and regulatory challenges are the barriers to implementation of these innovative treatments. Vaccines themselves are generally considered high risk with a low profit margin by the pharmaceutical industry, in large part because of the extended liability that a company can incur with the prolonged legal exposure produced through vaccination. Also, the fundamental stigma of substance abuse, viewed as a moral failure rather than a brain disease, pervades many aspects of treatment for substance abuse. When addiction is considered a failure of will power or as willful misconduct, then treatment is generally directed toward the behavioral disorder, with little consideration given to direct medical intervention, so that even the addict may not recognize the potential benefit of therapeutic vaccination. The economic correlate of this perception within the pharmaceutical industry is that these patients would provide a poor return on investment for the costs and risks of developing an immunological intervention. This misperception has been countered to a significant extent for tobacco smoking, possibly because of its legality and worldwide prevalence, and as a result, nicotine vaccines are in clinical trials by three companies.

Vaccines may have potential use as preventive agents in high-risk populations; however, certain ethical concerns need to be considered carefully before implementation in these contexts [72,73]. For examples, the treatment may be provided as an alternative to imprisonment to persons who have been charged with or convicted of an offence to which their drug dependence has contributed, its main justification being that treating offenders' drug dependence will reduce their chance of reoffending $[74,75]$. Another example could be vaccinating adolescents against nicotine. If the adolescents then subsequently smoked ten times more cigarettes in order to overcome the nicotine blockade, the result of such high levels of smoking for prolonged periods would be a massive increase of ingested carcinogens, which the vaccine does not block. Another possible application would be to use the vaccines in drug-abusing pregnant women to protect the fetus and mother from drug exposure and its complications. Finally, parents might request that their children be vaccinated to prevent future drug abuse, even though the risks of future drug abuse for them as individuals might not be well defined [73].

The ethical and legal challenges have made FDA approval for an anti-addiction vaccine extremely complicated, and the precise requirements for FDA approval are not clear because no such vaccine has yet been approved [74]. FDA approval requires demonstration of not only clinical efficacy, but also medical safety. The preventive use of a vaccine in healthy young people requires stronger evidence of safety and efficacy than shorter-term use to reduce relapse in adults who are drug dependent. Obtaining evidence to meet regulatory requirements for such use has become very expensive to accomplish $[74,75]$. As a result, FDA approval has been of great concern to those companies who might manufacture, license, and sell these vaccines.

\section{Conclusions}

The results from human studies of the first cocaine vaccine and three nicotine vaccines are promising, and preclinical development of efficacious methamphetamine and opiate vaccines is rapidly progressing. Blocking immediate behavioral and toxic drug effects is valuable, but even more promising from the addiction perspective is the inhibition of drug reinforcement, or craving, which will be necessary to help prevent relapse to drug use by individuals motivated to quit. Ethical, legal, and regulatory challenges are the barriers to implementation of anti-addition vaccines, and future development strategies may include examining additional ways to increase antibody levels in high proportions of immunized individuals to improve vaccine efficacy. Advances in vaccine conjugate design, carrier protein use, and especially adjuvant optimization will significantly enhance the quantity and quality of the antibodies produced, allowing drug vaccines to become useful clinical tools for the treatment of substance abuse.

\section{Abbreviations}

FDA, US Food and Drug Administration; KLH, keyhole limpet hemocyanin; OMPC, outer membrane protein complex of the bacterium Neisseria meningitidis group $\mathrm{B}$.

\section{Competing interests}

The authors declare that they have no competing interests.

\section{Acknowledgements}

Supported by the Department of Veterans Affairs (VA) Merit Review Program and VISN 16 Mental Illness 
Research, Education and Clinical Center (MIRECC), the VA National Substance Use Disorders Quality Enhancement Research Initiative (QUERI), and the National Institute on Drug Abuse grants K05 DA 0454 (TRK), P50-DA18197 (TRK), 5R01DA030338 (FMO), 1X02DA032939 (TRK, FMO, XYS), R01DA026859 (FMO, XYS).

\section{References}

I. United Nations Office on Drugs and Crime: World Drug Report 20I I. United Nations Publication, Sales No. E.I I.XI. I0. [http://www. unodc.org/documents/data-and-analysis/WDR20I I/World_Drug_ Report_20II_ebook.pdf]

2. Fox BS, Kantak KM, Edwards MA, Black KM, Bollinger BK, Botka AJ, French TL, Thompson TL, Schad VC, Greenstein JL, Gefter ML, Exley MA, Swain PA, Briner TJ: Efficacy of a therapeutic cocaine vaccine in rodent models. Nat Med 1996, 2: I 129-32.

FI000 Factor 6

Evaluated by Thomas Kosten 20 Sep 2011

3. Pentel PR, Malin DH, Ennifar S, Hieda $Y$, Keyler DE, Lake JR, Milstein JR, Basham LE, Coy RT, Moon JW, Naso R, Fattom A: A nicotine conjugate vaccine reduces nicotine distribution to brain and attenuates its behavioral and cardiovascular effects in rats. Pharmacol Biochem Behav 2000, 65:191-8.

FI000 Factor 6

Evaluated by Thomas Kosten 20 Sep 2011

4. Byrnes-Blake KA, Laurenzana EM, Carroll Fl, Abraham P, Gentry WB, Landes RD, Owens SM: Pharmacodynamic mechanisms of monoclonal antibody-based antagonism of (+)-methamphetamine in rats. Eur J Pharmacol 2003, 14:119-28.

FI000 Factor 6

Evaluated by Thomas Kosten 20 Sep $201 \mathrm{I}$

5. Laurenzana EM, Byrnes-Blake KA, Milesi-Hallé A, Gentry WB, Williams DK, Owens SM: Use of anti-(+)-methamphetamine monoclonal antibody to significantly alter $(+)$-methamphetamine and (+)-amphetamine disposition in rats. Drug Metab Dispos 2003, 31:1320-6.

FI000 Factor 6

Evaluated by Thomas Kosten 20 Sep 2011

6. Laurenzana EM, Hendrickson HP, Carpenter D, Peterson EC, Gentry WB, West M, Che Y, Carroll FI, Owens SM: Functional and biological determinants affecting the duration of action and efficacy of anti-(+)-methamphetamine monoclonal antibodies in rats. Vaccine 2009, 27:70II-20.

FI000 Factor 6

Evaluated by Thomas Kosten 20 Sep 2011

7. Berkowitz B, Spector S: Evidence for active immunity to morphine in mice. Science 1972, I78:1290-2.

FI000 Factor 8

Evaluated by Thomas Kosten 20 Sep 2011

8. Bonese KF, Wainer BH, Fitch FW, Rothberg RM, Schuster CR: Changes in heroin self-administration by a rhesus monkey after morphine immunisation. Nature 1974, 252:708-10.

FI000 Factor 8

Evaluated by Thomas Kosten 20 Sep 2011

9. Kreek MJ, Borg L, Ducat E, Ray B: Pharmacotherapy in the treatment of addiction: methadone. J Addict Dis 2010, 29:200-16.

10. Minozzi S, Amato L, Vecchi S, Davoli M, Kirchmayer U, Verster A: Oral naltrexone maintenance treatment for opioid dependence. Cochrane Database Syst Rev 20II, 2:CD00I333.
II. Maurer P, Bachmann MF: Vaccination against nicotine: an emerging therapy for tobacco dependence. Expert Opin Investig Drugs 2007, 16:1775-83.

12. Hatsukami DK, Jorenby DE, Gonzales D, Rigotti NA, Glover ED, Oncken CA, Tashkin DP, Reus VI, Akhavain RC, Fahim RE, Kessler PD, Niknian M, Kalnik MW, Rennard SI: Immunogenicity and smoking-cessation outcomes for a novel nicotine immunotherapeutic. Clin Pharmacol Ther 20II, 89:392-9.

FI000 Factor 6

Evaluated by Thomas Kosten 20 Sep 2011

13. Haney M, Kosten TR: Therapeutic vaccines for substance dependence. Expert Rev Vaccines 2004, 3:1 I-8.

14. Orson FM, Kinsey BM, Singh RA, Wu Y, Gardner T, Kosten TR: Substance abuse vaccines. Ann N Y Acad Sci 2008, I | 41:257-69.

15. Kosten TR, Biegel D: Therapeutic vaccines for substance dependence. Expert Rev Vaccines 2002, I:363-7I.

16. Substance Abuse and Mental Health Services Administration: Results from the 2005 National Survey on Drug Use and Health: National Findings. Office of Applied Studies, NSDUH Series H-30, DHHS Publication No. SMA 06-4194. Rockville, MD; 2006. [http://oas. samhsa.gov/nsduh/2k5nsduh/2k5Results.htm]

17. Karila L, Gorelick D, Weinstein A, Noble F, Benyamina A, Coscas S, Blecha L, Lowenstein W, Martinot JL, Reynaud M, Lépine JP: New treatments for cocaine dependence: a focused review. Int J Neuropsychopharmacol 2008, I I:425-38.

FI000 Factor 6

Evaluated by Thomas Kosten 20 Sep 2011

18. Martell BA, Orson FM, Poling J, Mitchell E, Rossen RD, Gardner T, Kosten TR: Cocaine vaccine for the treatment of cocaine dependence in methadone-maintained patients: a randomized, double-blind, placebo-controlled efficacy trial. Arch Gen Psychiatry 2009, 66: I I 16-23.

FI000 Factor 8

Evaluated by Harriet de Wit 3I Dec 2009

19. Martell BA, Mitchell E, Poling J, Gonsai K, Kosten TR: Vaccine pharmacotherapy for the treatment of cocaine dependence. Biol Psychiatry 2005, 58: I58-64.

20. Haney M, Gunderson EW, Jiang H, Collins ED, Foltin RW: Cocainespecific antibodies blunt the subjective effects of smoked cocaine in humans. Biol Psychiatry 2010, 67:59-65.

FI000 Factor 6

Evaluated by Thomas Kosten 20 Sep 2011

2I. Stewart DJ, Inaba T, Lucassen M, Kalow W: Cocaine metabolism: cocaine and norcocaine hydrolysis by liver and serum esterases. Clin Pharmacol Ther 1979, 25:464-8.

FI000 Factor 6

Evaluated by Thomas Kosten 20 Sep 2011

22. Williams RH, Maggiore JA, Shah SM, Erickson TB, Negrusz A: Cocaine and its major metabolites in plasma and urine samples from patients in an urban emergency medicine setting. J Anal Toxicol 2000, 24:478-8I.

23. Esson L, SR Leeder: The millennium development goals and tobacco control: an opportunity for global partnership. Geneva: World Health Organization (WHO); 2004.

24. Tobacco Free Initiative (TFI): Why is tobacco a public health priority? World Health Organization (WHO); 2005. [http://www. who.int/tobacco/health_priority/en]

25. Aubin HJ, Karila L, Reynaud M: Pharmacotherapy for smoking cessation: present and future. Curr Pharm Des 2011, 17:1343-50.

26. Hays JT, Ebbert JO: Adverse effects and tolerability of medications for the treatment of tobacco use and dependence. Drugs 2010, 70:2357-72.

27. Centers for Disease Control and Prevention: 2004 Surgeon General's Report-The Health Consequences of Smoking. [http://www.cdc.gov/tobacco/data_statistics/sgr/2004/index.htm] 
28. Hieda $Y$, Keyler DE, Ennifar S, Fattom A, Pentel PR: Vaccination against nicotine during continued nicotine administration in rats: immunogenicity of the vaccine and effects on nicotine distribution to brain. Int J Immunopharmacol 2000, 22:809-19.

FI000 Factor 6

Evaluated by Thomas Kosten 20 Sep 2011

29. Polosa R, Benowitz NL: Treatment of nicotine addiction: present therapeutic options and pipeline developments. Trends Pharmacol Sci 20II, 32:28I-9.

FI000 Factor 6

Evaluated by Thomas Kosten 20 Sep 2011

30. Cornuz J, Zwahlen S, Jungi WF, Osterwalder J, Klingler $K$, van Melle G, Bangala $Y$, Guessous I, Müller P, Willers J, Maurer P, Bachmann MF, Cerny T: A vaccine against nicotine for smoking cessation: a randomized controlled trial. PLoS One 2008, 3: e2547.

FI000 Factor 6

Evaluated by Thomas Kosten 20 Sep 2011

31. Cytos Biotechnology: CYT002 Nic Qb: a novel vaccine for nicotine addiction. Zurich: Cytos Biotechnology; 2006. [http:// www.cytos.com/doc/NicQb_June06_E_fv.pdf]

32. Nabi Biopharmaceuticals: Clinical Trials: NicVAX® (Nicotine Conjugate Vaccine). [http://www.nabi.com/pipeline/clinicaltrials. php]

33. Nabi Biopharmaceuticals: News Release: Nabi Biopharmaceuticals Announces Results of First NicVAX(R) Phase III Clinical Trial. Smoking Cessation Immunotherapy Failed to Meet Primary Endpoint. [http://phx.corporate-ir.net/phoenix.zhtml? $c=100445$ \& $=$ =irol-newsArticle\&ID $=\mid$ | 58600 | \&highlight $=$ ]

34. Darke S, Kaye S, McKetin R, Duflou J: Major physical and psychological harms of methamphetamine use. Drug Alcohol Rev 2008, 27:253-62.

35. Fowler JS, Volkow ND, Logan J, Alexoff D, Telang F, Wang GJ, Wong C, Ma Y, Kriplani A, Pradhan K, Schlyer D, Jayne M, Hubbard B, Carter P, Warner D, King P, Shea C, Xu Y, Muench L, Apelskog K: Fast uptake and long-lasting binding of methamphetamine in the human brain: comparison with cocaine. Neuroimage 2008, 43:756-63.

FI000 Factor 6

Evaluated by Thomas Kosten 20 Sep 2011

36. Cook CE, Jeffcoat AR, Hill JM: Pharmacokinetics of methamphetamine self-administered to human subjects by smoking S- (I) -methamphetamine hydrochloride. Drug Metab Dispos 1993, $21: 717-23$.

37. Volkow ND, Fowler JS, Wang GJ, Shumay E, Telang F, Thanos PK, Alexoff D: Distribution and pharmacokinetics of methamphetamine in the human body: clinical implications. PLoS One 2010, 5:el5269.

FI000 Factor 6

Evaluated by Thomas Kosten 20 Sep 2011

38. Fowler JS, Kroll C, Ferrieri R, Alexoff D, Logan J, Dewey SL, Schiffer W, Schlyer D, Carter P, King P, Shea C, Xu Y, Muench L, Benveniste H, Vaska P, Volkow ND: PET studies of d-methamphetamine pharmacokinetics in primates: comparison with I-methamphetamine and (-)-cocaine. J Nucl Med 2007, 48: 1724-32.

FI000 Factor 6

Evaluated by Thomas Kosten 20 Sep 2011

39. Karch SB: Karch's Pathology of Drug Abuse - Fourth Edition. Boca Raton, FL: CRC Press; 2008.

40. Quinn DI, Wodak A, Day RO: Pharmacokinetic and pharmacodynamic principles of illicit drug use and treatment of illicit drug users. Clin Pharmacokinet 1997, 33:344-400.
4I. Gonzales R, Mooney L, Rawson RA: The methamphetamine problem in the United States. Annu Rev Public Health 2010, 31:385-98.

FI000 Factor 6

Evaluated by Thomas Kosten 20 Sep 2011

42. McKetin R, Kozel N, Douglas J, Ali R, Vicknasingam B, Lund J, Li JH: The rise of methamphetamine in Southeast and East Asia. Drug Alcohol Rev 2008, 27:220-8.

FI000 Factor 6

Evaluated by Thomas Kosten 20 Sep 2011

43. Meijler MM, Matsushita M, Wirsching P, Janda KD: Development of immunopharmacotherapy against drugs of abuse. Curr Drug Discov Technol 2004, 1:77-89.

FI000 Factor 6

Evaluated by Thomas Kosten 20 Sep 2011

44. Substance Abuse and Mental Health Services Administration: Results from the 2008 National Survey on Drug Use and Health: National Findings. Office of Applied Studies, NSDUH Series H-36, HHS Publication No. SMA 09-4434. Rockville, MD; 2009. [http://oas. samhsa.gov/nsduh/2k8nsduh/2k8Results.cfm]

45. US Department of Justice, National Drug Intelligence Center: National Drug Threat Assessment 2003. Johnstown, PA: National Drug Intelligence Center; 2003. [http://www.justice.gov/ndic/pubs3/3300/ index.htm]

46. Byrnes-Blake KA, Carroll Fl, Abraham P, Owens SM: Generation of anti-(+)methamphetamine antibodies is not impeded by $(+)$ methamphetamine administration during active immunization of rats. Int Immunopharmacol 200 I, I:329-38.

FI000 Factor 6

Evaluated by Thomas Kosten 20 Sep 2011

47. Moreno AY, Mayorov AV, Janda KD: Impact of distinct chemical structures for the development of a methamphetamine vaccine. J Am Chem Soc 20II, 133:6587-95.

FI000 Factor 6

Evaluated by Thomas Kosten 20 Sep 2011

48. Peterson EC, Gunnell M, Che Y, Goforth RL, Carroll FI, Henry R, Liu H, Owens SM: Using hapten design to discover therapeutic monoclonal antibodies for treating methamphetamine abuse. J Pharmacol Exp Ther 2007, 322:30-9.

FI000 Factor 6

Evaluated by Thomas Kosten 20 Sep 2011

49. Owens SM, Mayersohn M: Phencyclidine-specific Fab fragments alter phencyclidine disposition in dogs. Drug Metab Dispos 1986, 14:52-8.

50. McMillan DE, Hardwick WC, Li M, Gunnell MG, Carroll FI, Abraham P, Owens SM: Effects of murine-derived anti-methamphetamine monoclonal antibodies on (+)-methamphetamine selfadministration in the rat. J Pharmacol Exp Ther 2004, 309:1248-55.

51. Byrnes-Blake KA, Laurenzana EM, Landes RD, Gentry WB, Owens SM: Monoclonal IgG affinity and treatment time alters antagonism of (+)-methamphetamine effects in rats. Eur J Pharmacol 2005, 521:86-94.

52. Gentry WB, Laurenzana EM, Williams DK, West JR, Berg RJ, Terlea T, Owens SM: Safety and efficiency of an anti-(+)methamphetamine monoclonal antibody in the protection against cardiovascular and central nervous system effects of (+)-methamphetamine in rats. Int Immunopharmacol 2006, 6:968-77.

53. Coffman RL, Sher A, Seder RA: Vaccine adjuvants: putting innate immunity to work. Immunity 2010, 33:492-503.

54. Leshner Al: Comments on "The moral economies of homeless heroin addicts: confronting ethnography, HIV risk, and 
everyday violence in San Francisco shooting encampments". by Phillippe Bourgois. Subst Use Misuse 1998, 33:2369-74.

FI000 Factor 6

Evaluated by Thomas Kosten 20 Sep 2011

55. Tang YL, Zhao D, Zhao C, Cubells JF: Opiate addiction in China: current situation and treatments. Addiction 2006, 101:657-65.

FI000 Factor 6

Evaluated by Thomas Kosten 20 Sep 2011

56. Substance Abuse and Mental Health Services Administration: Results from the 2007 National Survey on Drug Use and Health: National Findings. Office of Applied Studies, NSDUH Series H-34, DHHS Publication No. SMA 08-4343. Rockville, MD; 2008. [http://oas. samhsa.gov/nsduh/2k7nsduh/2k7Results.cfm]

57. Dekimpe MG, Van de Gucht LM, Hanssens DM, Powers KI: Long run abstinence after narcotics abuse: What are the odds? Manag Sci 1998, 44: 1478-92.

FI000 Factor 6

Evaluated by Thomas Kosten 20 Sep 2011

58. Gossop M, Stewart D, Browne N, Marsden J: Factors associated with abstinence, lapse or relapse to heroin use after residential treatment: protective effect of coping responses. Addiction 2002, 97:1259-67.

FI000 Factor 6

Evaluated by Thomas Kosten 20 Sep 201

59. Maxwell S, Shinderman MS: Optimizing long-term response to methadone maintenance treatment: a 152-week follow-up using higher-dose methadone. J Addict Dis 2002, 21:1-12.

FI000 Factor 6

Evaluated by Thomas Kosten 20 Sep 2011

60. Mark TL, Woody GE, Juday T, Kleber HD: The economic costs of heroin addiction in the United States. Drug Alcohol Depend 200I, 61:195-206

FI000 Factor 6

Evaluated by Thomas Kosten 20 Sep 2011

61. Van Vunakis H, Wasserman E, Levine L: Specificities of antibodies to morphine. J Pharmacol Exp Ther 1972, 180:514-21.

FI000 Factor 6

Evaluated by Thomas Kosten 20 Sep $201 \mathrm{I}$

62. Wainer BH, Fitch FW, Fried J, Rothberg RM: A measurement of the specificities of antibodies to morphine-6-succinyl-BSA by competitive inhibition of $14 \mathrm{C}$-morphine binding. I Immunol 1973, I 10:667-73.

FI000 Factor 6

Evaluated by Thomas Kosten 20 Sep 2011

63. Koida M, Takahashi M, Muraoka S, Kaneto H: Antibodies to BSA conjugates of morphine derivatives: strict dependency of the immunological specificity on the hapten structure. Jpn J Pharmacol 1974, 24:165-7.

FI000 Factor 6

Evaluated by Thomas Kosten 20 Sep 2011

64. Akbarzadeh A, Mehraby M, Zarbakhsh M, Farzaneh H: Design and synthesis of a morphine-6-succinyl-bovine serum albumin hapten for vaccine development. Biotechnol Appl Biochem 1999, 30:139-46.

FI000 Factor 6

Evaluated by Thomas Kosten 20 Sep 2011

65. Anton B, Leff P: A novel bivalent morphine/heroin vaccine that prevents relapse to heroin addiction in rodents. Vaccine 2006 , 24:3232-40.

FI000 Factor 6

Evaluated by Thomas Kosten 20 Sep 2011

66. Ma LX, Zhou Q, Zheng HB, Li SB: Preparation and characterization of anti-morphine vaccine antibody. Xi Bao Yu Fen Zi Mian $Y_{i}$ Xue Za Zhi 2006, 22:368-70.

FI000 Factor 6

Evaluated by Thomas Kosten 20 Sep 2011

67. Stowe GN, Vendruscolo LF, Edwards S, Schlosburg JE, Misra KK, Schulteis G, Mayorov AV, Zakhari JS, Koob GF, Janda KD: A Vaccine Strategy that Induces Protective Immunity against Heroin. J Med Chem 20II, 54:5I95-204.

FI000 Factor 6

Evaluated by Thomas Kosten 20 Sep 2011

68. Shen X, Lopez A, Kinsey BM, Singh RA, Wu Y, Mao B, Orson FM: Morphine Vaccination and Inhibition of Morphine Induced Analgesia in Mice [abstract]. Presented at 13th World Vaccine Congress: March 20I I; Beijing, China; 34I.

69. Shen X, Kosten TA, Lopez AY, O'Malley PW, Wu Y, Kinsey BM, Orson FM: Morphine vaccination and its inhibition of morphine induced CPP and analgesia in rats [abstract]. Presented at 73rd Annual Meeting of the College on Problems of Drug Dependence: 18-23 June 20II; Hollywood, FL.

70. Inturrisi CE, Schultz M, Shin S, Umans JG, Angel L, Simon E): Evidence from opiate binding studies that heroin acts through its metabolites. Life Sci 1983, 33(Suppl I):773-6.

FI000 Factor 6

Evaluated by Thomas Kosten 20 Sep 2011

7I. de Wit H: Priming effects with drugs and other reinforcers. Exp Clin Psychopharmacol 1996, 4:5-10.

FI000 Factor 6

Evaluated by Thomas Kosten 20 Sep 2011

72. Hall W, Carter L: Ethical implications of using a cocaine vaccine to treat and prevent cocaine dependence. J Med Ethics 2004, 30:337-40.

FI000 Factor 6

Evaluated by Thomas Kosten 20 Sep 2011

73. Hall W, Gartner C: Ethical and policy issues in using vaccines to treat and prevent cocaine and nicotine dependence. Curr Opin Psychiatry 201I, 24:191-6.

FI000 Factor 6

Evaluated by Thomas Kosten 20 Sep 2011

74. Edited by Harwood HJ, Myers TG: National Research Council \& Institute of Medicine: New Treatments for Addiction: Behavioral, Ethical, Legal, and Social Questions. Washington, DC: National Academies Press; 2004.

75. Spooner C, Hall W, Mattick RP: An overview of diversion strategies for Australian drug related offenders. Drug Alcohol Rev 200I, 20:281-94.

FI000 Factor 6

Evaluated by Thomas Kosten 20 Sep 2011 